\title{
THE OPINIONS OF UNIVERSITY TEACHERS TO THE GOALS AND ROLE OF FEEDBACK GIVEN BY STUDENTS TOWARDS THEIR PROFESSIONAL DEVELOPMENT AND EXPECTATIONS FOR IMPROVING THE FEEDBACK SYSTEM
}

\author{
Marit Sepma ${ }^{1}$, Liina Lepp ${ }^{2}$, Marvi Remmik ${ }^{3}$ \\ 1,2,3 University of Tartu (ESTONIA)
}

\begin{abstract}
Collecting feedback on the organization and content of teaching creates a base for university teachers' development. The aim of this study was to describe the university teachers' opinions to the feedback given by students and its' meaning on their professional development point out teachers' suggestions for the development of the feedback system. Twelve university teachers were interviewed and the data were analyzed using qualitative thematic analysis. The results point that in one hand feedback is seen as a chance for professional development and in the other hand, it is considered to be a mean of external control which can lead to decisions about the human resources within the department. University teachers who took part in this interview suggested various topics on how to develop the feedback system. Including the need to make giving feedback obligatory in all of the universities courses and disclaim the obligation for anonymity to improve the reliability of the answers. Furthermore, raise the proportion of opened questions in the feedback form.
\end{abstract}

Keywords: University student feedback, professional development, feedback system

\section{INTRODUCTION}

Collecting feedback on the organization and content of curricular activities creates a base for increasing the quality of the studies and for university teachers' professional development. Therefore it helps with taking the needs of the students and the society into account [1]. Although collecting student feedback is very important, it is not always based on scientific methods and is not reliable [2]. Unreliable student feedback can cause errors in interpreting the results of the feedback and making decisions on curricular improvement [3] and can have a negative influence on the professional development of the university teacher as a whole [4]. Previous studies have shown that student feedback does not always lead the university teachers to change their teaching. For example, Marsh found no overall increase of student ratings of teaching over time [1]. According to Karm and colleagues, negative feedback can bring forth feelings of frustration and can be emotionally damaging. It could also lead to decreasing the desire to make developments in their teaching [4]. Due to that, it is important to systematically improve the feedback system within universities, taking the teachers expectations towards collecting feedback into account.

This article focuses on the feedback that universities collect centrally from students about factors in their studies. The aim of this study was to describe the university teachers' opinions to the feedback given by students and its' meaning on their professional development and to point out teachers' suggestions for development of the feedback system.

\subsection{Theoretical background}

There are many purposes of collecting feedback about the universities lecturers that can be targeted towards giving an appraisal to academic activities and to future development [5]. Systematically collected reliable feedback gives diverse information to lecturers, universities and students themselves. Therefore, giving them an opportunity to improve both studying and teaching.

For example, teachers can have an overview of the estimated quality of their academic work through the feedback given by their students. This gives them the capacity to have an overview of their professional development and make improvements in conducting the studies (calculated decisions about improving their academic work) [1]. Teachers have an opportunity to learn more about the 
preference and satisfaction of their students throughout the given feedback $[6,7]$ and take that into consideration when compiling and carrying out their work. Next, to that, feedback can help lecturers to reflect on themselves and acknowledge what is positive and negative about their methods of teaching.

From the students' point of view, collecting feedback has various positive aspects. Even the fact that the students are asked about their feedback gives them a signal of the importance of their opinion which leads to improvements in their satisfaction about their studies and the university as a whole [8]. In a wider perspective, giving feedback is one of the channels through which students can give out their opinion and statements about the courses and the way they are conducted. Hence, they feel more involved in the management of the university [10]. The contemporary way of teaching is based on self-conducting [11], where giving a student the feeling of ownership is one of the most important assumptions. Asking feedback from students and analyzing the results gives a great opportunity to start or encourage self-conducting studying among students.

Universities as a whole can get some insight through student feedback for making decisions about their leadership. For example, evaluating their staff and decisions considering staff politics [1, 12]. In the long run, it is targeted towards raising the quality of the studies - universities can improve their study programmes and guide teachers to self-development considering the student feedback.

There are numerous ways for collecting feedback from students - one dominant method has not been developed. Still, some overall characteristics can be brought out to describe the feedback system. For example, in most top universities feedback is collected in writing, where students fill it in at the end of the semester [6]. Quantitative feedback is mostly collected from students in writing [6] although it is still sometimes used to collect qualitative feedback as well [10]. Feedback forms that are in writing are largely based on scale questions where students have to give feedback in a five-point or ten-point scale about different aspects in their courses and the work of their teachers [6]. Next, to that, multiplechoice question forms can be used as well. Also, there can be open-form questions, where students can give out their opinion in a free form of the way [9]. Feedback forms in writing are nowadays usually based online, although student feedback can also be collected on paper [13].

Regardless of in what way the feedback is collected one of the key things to developing the quality of studying and making changes in teaching is the teacher's attitude towards the given feedback. For teachers to take the feedback into consideration they have to consider it trustworthy and think, that student feedback is needed and should be reckoned with [15]. Earlier empirical studies have found, that the teacher's attitude towards student feedback can be different. In case of a positive attitude teachers usually take the student feedback into consideration. In case of a negative attitude, the student feedback tends to be ignored $[4,15,16]$. Thereat, it has been found that teachers who have a more positive attitude towards student feedback are the ones who get higher scores and more positive feedback from students [17]. Also, the teacher's attitude towards student feedback depends on if they consider the method of collecting the feedback reliable or not [15]. Teachers with the negative attitude towards student feedback usually think that students do not have enough knowledge and experience to judge the teacher's work $[4,18]$.

Next to the way of collecting and the teacher's attitude about the feedback it is also important how the feedback is understood. In cases, where the teachers are unsure about how the feedback should be taken into consideration in conducting their work [10] there can be unnecessary attention given to small details [19] or have trouble putting the given feedback into correct context [20]. It has been found, that teachers value qualitative feedback more [4] and in quantitative feedback, it is important for teachers to find a corresponding comparison. For example, feedback given about a course with a similar level of difficulty [17].

Since collecting feedback plays an important role in developing the study process and earlier studies have shown conflicting results and the qualitative feedback method has not been studied in an extent about the feedback given by students, its' meaning in their professional development and bring out known to the examiner, the aim of this study was to describe the university teachers' opinions to the feedback given by students and its' meaning on their professional development point out teachers' suggestions for development of the feedback system. 
This aim was approached with the following research questions:

1. What kind of goal is achieved to you as a teacher when student feedback is collected centrally?

2. How do teachers describe centrally collected student feedbacks' importance in their professional development?

3. What kind of recommendations do teachers give to improve the centrally collected feedback? An overview is given of the feedback systems used in the University of Tartu before introducing the studies methodic and results. This study is only focused on the centrally collected feedback in the University of Tartu. Therefore, other feedback that the teachers might collect is not being considered.

\subsection{Teaching and the courses feedback system in the University of Tartu}

In the Republic of Estonia, which has 1.3 million citizens, there are six public universities. The University of Tartu, which student feedback is the main subject of this study is the biggest and oldest university in Estonia. There were 12674 students in the year of 2016/2017 [21] and 1400 academic employees, including 201 professors. In the university, there are four departments: Faculty of Arts and Humanities, Faculty of Social Sciences, Faculty of Medicine, Faculty of Science and Technology. The University of Tartu is in the top $2 \%$ of the worlds' universities [22].

Since 2006 students from all levels in the University of Tartu have the chance to give anonymous feedback about teaching and the course at the end of the semester in writing through the studies info system (ÕIS). The university has set five goals for the feedback enquiry: give feedback to teachers to improve the subjects; to find mistakes in the teaching and improve the management of study development actions; get information to make decisions about study and staff work; guide and create the teachers' and students' understanding about great teaching; improve students' self-analysing skills [23].

Students have the opportunity to give out feedback from two weeks before the semesters' exams to the beginning of the next semester. Each student has to assess at least four of each semesters courses in baccalaureate or master studies and only one course in doctoral-studies [24].

The feedback questionnaire consists of: 1) questions about the students work in a course (selfanalysis/time-management, achieving study goals) 2) questions about teachers 3 ) questions about the course. Answering the 12 multiple-choice questions is mandatory for the student. Students can give recommendations to future students (example question: What would you say about the course to future students?). Furthermore, in case of multiple-choice questions, the students can also comment or substantiate their answers. In case the student does not give feedback that is required, their access to the study info system is limited. For example, the student can not register for courses and can not see timetables, study materials etc. All the multiple-choice questions are available for teachers, curriculum manager, head of departments and other accredited people [23].

People who have entered the study info system have access to the feedback given about courses in graphics, where all the questions' answers have been brought out in histograms and line graphs. Next, to that, there are medium values given about the answers and the percentage ranking in comparison to the other courses [24]. Detailed information about the feedback results graph can be found here: http://lingid.ee/graphUT.

\section{METHODOLOGY}

The participants were 12 university teachers from the University of Tartu. The purposive sample was used. The researcher included participants from different faculties and with varied tenure to the sample. Three of the participants were from the Faculty of Medicine, 7 from Faculty of Social Sciences and 2 from Faculty of Science and Technology.There were 6 women and 6 men among the participants and they all were between the ages of 32-68. The shortest working experience was 1 year, the longest 19 years.

The data were collected in the middle of the fall semester (November-December of 2017) by semistructured individual interviews. That means that the last feedback the participants received from the study info system was 5-6 months before the interviews took place. The interviews plan was separated into three subject blocks: the first one included questions about the goals of collecting the feedback (example question: Who do you think gets the most benefit from collecting the student 
feedback?), the second block focused on the experiences connected to collecting student feedback (example question: What kind of emotions does the given student feedback make you feel?) and the third block was about the reliability of the student feedback (example question: What could be done about collecting the feedback from students in the University of Tartu to make it more reliable?)

The initial interview plan was introduced to colleagues, who are also teachers, to get some advice and feedback. Secondly, some changes were made to the interview plan. After that, a pilot interview was conducted with a teacher who fit the criteria. Major changes were not made after the pilot interview which makes the interview a part of the data. The interview plan can be found here: http://lingid.ee/interviewplan. The interviews on average were over an hour long and they were recorded with the participant's permission. The interviews were analyzed using qualitative thematic analysis according to Braun and Clarke's data analysing steps [25].

To increase the quality of the study, the interview plan was discussed with subject fields experts and a pilot interview was conducted. To increase the trustworthiness of the study the researcher filled out a researchers diary throughout the whole process. The collecting of data and data analysis were reflected. To allow transferability, the context of this research (feedback system used in the University of Tartu) is described in detail and direct quotations from interviews are brought out when describing the results.

Next, the results of this research are given in the main research goals. To illustrate and validate the results there are direct quotations added from the interviews. The quotations have been edited to not include repetitive phrases. At the end of each quotation, there is a letter and a number in brackets. For example, M1 which refers to a participant from the Faculty of Medicine and the number 1 to the first conducted interview. For the participant from the Faculty of Social Science letters SS are used and for the Faculty of Science and Technology letters ST are used.

\section{RESULTS AND DISCUSSION}

\subsection{Goals of collecting feedback from students}

The research question "What kind of goal does asking for feedback from students achieve to teachers?" the results are divided into two larger themes. According to the participants' opinion the feedback is collected for 1) to control and evaluate the study process and 2) to improve the study process. Based on the interviews, teachers, students, the universities structural leaders and the university as a whole are the ones who are mostly benefited from collecting student feedback.

Teachers who participated in this study said, that trough trustworthy and calculated feedback it is possible to control teachers' professionality and the quality of their work and trough that the quality of the conducting of the studies. Collected feedback can also bring out information that according to the participants can be used to bring back teachers. Calculated and trustworthily collected student feedback is said to be a tool to improve the study process through the teachers professional development and give valuable reason to develop the study system as a whole. Feedback gives the opportunity to make changes in the conducting of study work and subject programs in the future. Therefore, feedback is beneficial to students, because the studies are improved through developing teachers professional skills and also the overall improvement of subject programs makes them more in accord to the likes and needs of the students. Participants in this study brought out that it is possible only in case the teachers and leaders of the structural unit take the given feedback into consideration and make changes accordingly.

Similarly, student feedbacks' goals have been brought out in earlier studies $[1,5,6,7,12]$ and the authors have brought out students, teachers and the universities as the benefiters from the feedback $[1,6,8,10]$. What can be said is new, is the fact, that society as a whole benefit from student feedback. This aspect has not been brought out in previous studies on this subject.

In case it worked, everyone would benefit from it - the university, teachers, students. The study environment would improve. The length and colour of a dress can not be compared. Different dimensions benefit equally (SS10).

What is interesting in the results of this study is that many participants pointed out the importance of reliability and calculation and how well the system works when it comes to the goals of student feedback. This proves the importance of taking teachers opinions into consideration when working out the feedback system. These results match with the previous studies $[14,18]$ that have also shown that 
teachers think that the methodology and reliability of the student feedback are important. Therefore, their attitude towards student feedback is based on how reliable the teacher thinks the feedback system is.

\subsection{Impact of student feedback on the teachers professional development}

The results of the research question "How do teachers describe the impact of student feedback to their professional development?" are divided into three themes. According to the participants of this study, the feedback has been: 1) supportive towards the teachers' professional development, 2) neutral (has not triggered changes), 3) made them insecure as teachers

Previous studies have shown that the teachers' attitude towards student feedback has been both positive [16] and negative [18]. In this study, the teachers also brought out different aspects that mainly stated the importance of the way the feedback system is conducted. The teachers stated that their attitude towards the feedback depends on the way it is collected.

One part of the teachers explained, that the feedback that has supported their professional development are the ones that they interpreted as positive. Teachers from this group stated, that since the students are the ones who actually go through the study process, their opinions matter and their feedback is very valuable.

If somebody knows what goes on in the auditorium, it is the student. No matter how many consultants or observers there are, the only one who sees the whole process is still the student. I do not think the students are dumb. Not dumb enough to not have an opinion on how things should be taught and what is right or wrong (SS1).

Because of this, the teachers are prepared to reflect on critical and straightforward feedback. Therefore, feedback that is interpreted as positive and supportive towards a teachers development does not always mean that the feedback has high scores. Rather, that the teacher understands what needs to be changed according to students and comments explaining the feedback that are the same from numerous students shows a sense of generality. The feedback that is interpreted as positive has made the participants feel more confident about themselves as teachers, given more enthusiasm to teach and also the urge to develop themselves even more. The main changes that were made according to the feedback were related to the general composition of the student work. For example, the number of seminars rose and lectures were substituted with home reading. As well as activities in the classroom, the explanations of the exercises have been made more understandable for students and giving more detailed explanations about given tasks. (With the following study groups, according to the previous groups' opinions) Teachers, who valued student feedback brought out that they always wait for the feedback and work with it thoroughly.

I made changes to the following course. I have been explaining from the start what and why we are doing/.../ have taken two steps back, to the level of a washing machine instruction (SS10).

The second part of the participants found, that they usually perceive feedback the way that does not trigger the change in their way of teaching (the feedback is neutral/does not increase or decrease the urge to teach/a wish to develop as a teacher). In the justification it was brought out that the explanations divide into two groups, often times combined: 1 ) little trust towards the feedback system (For example, the way it is collected and the timing, number of answers) (look 3.3) and 2) the selfconsciousness of the teacher (being aware of the way they teach and not needing any more feedback). The participants explained, that they are confident as teachers and are aware of their ways of teaching so they do not need extra feedback collected by someone else. It was brought out that if they feel the need for feedback then they have a choice as teachers to ask for it during the course.

A lot of previous studies' results have shown that when a teachers attitude towards the feedback is negative then there are no changes made by the feedback $[4,15,16]$. In this study, the results also show that when the feedback system is not trusted then no changes are usually made in the way of teaching. So it is important, that the feedback system is trustworthy to the teacher. One of the ways to get there is to conduct prolegomenous conversations about different feedback systems and collect teachers opinions about what should be changed in the feedback system.

The third opinion group consisted of answers where teachers described that feedback received from the students was extremely critical of them and it being demotivating and has made planning out and conducting the studies more groping. It was also explained, that even when the overall feedback was 
appreciative towards the teacher, a few extremely critical comments and low scores that were way below the average scores can cause negative feelings. Furthermore, a public comparison to colleagues (graphics in the study info system) is demotivating in case the scores are not that high.

If feedback is negative then some teachers are definitely uncertain about themselves for some time.

In case of negative feedback I form a protective position. If I do things well enough and if I am understood (SS7).

Therefore, the results of this study state that emotions are related to the content of the feedback. Positive feedback induces positive emotions and is supportive and motivating to the teachers. Moderate and constructive criticism has a rather positive affect and directs teachers to change, but only in case, the teachers feel that the feedback is collected in methodological bases and is reliable to them. In case the feedback is largely critical it starts to lower the motivation of the teachers and does not make the change in the way of teaching.

Richardson has brought a problem in the teacher feedback, they are not usually thought how to interpret the given feedback and how to react to it [10]. This studies' results point that there might be some shortages in the teacher's aptness to use the feedback to their benefit. Therefore, the authors of this paper think it is important to think about the ways teachers receive the feedback, in what form it is presented. One of the options is to use an opportunity to have consultations on interpreting the student feedback where a certified consultant can reflect on the feedback that has been given to the teacher and helps to find points to take into account in their professional development (what should be taken into account when planning and conducting the studies).

\subsection{Teachers recommendations to improve the student feedback system}

The answers of the research question "What kind of recommendations do teachers give to improve centrally collected student feedback?" are divided into three themes: 1) recommendations about the management of collecting the feedback (the number of answers, anonymity, time when it is collected); 2) conceptional recommendations about the collected feedback (answers in writing, difference between subjects, an option for the teacher to add questions); 3) recommendations about including the teachers and students into the process.

1) Recommendations about the management of collecting the feedback in this study pointed out 1) the lack of questions (the need to increase the number of questions) because the feedback system at the moment does not give the opportunity to generalize the results to improve the subject and the teacher. It was found that even though it is mandatory for the students to give feedback about the teachers, they still only have to pick out four subjects and because of that, some subjects receive way less feedback than the others and it is not possible to generalize the results. Johnson has also stated, that a low rate of answers can give unfair results [26].

It is a matter of numbers when only 4 students out of a 25 student group have given their opinion then to me it is not the kind of feedback that I am going to make generalizations by. (SS3).

It was a popular opinion among the participants, that because students can choose, what subjects they want to give feedback to then they only give out the extremes - these students who have enjoyed the course and the ones that are unsatisfied. According to this, the participants think that the real judgement of the students - opinion and recommendations of all students - is not received.

The second part of the participants thought, that when giving feedback is made mandatory for every course the students will start giving feedback unwillingly and not concentrating, just to get it over with and move on. Contextual feedback would still not be given to the teachers. So, it can not be stated according to this study, that teachers recommend increasing the overall number of answers.

If someone really wants to give feedback, they will either way. It should not be made mandatory. I myself have once thicked some boxes randomly all threes (M7).

This means that there is some controversiality in the answers given by the participants. In one hand, they think the feedback should be made mandatory to raise the number of answers, but on the other hand, it is said that making it mandatory makes the students give cursory feedback.

The participants brought out next to the lack of questions in the recommendations about the management of collecting the feedback the anonymity of the answers. In the participants, there were teachers who think that anonymous feedback gives the students the opportunity to not be thorough in 
their answers and therefore, loses the teachers opportunity to analyze the reasons of the given criticism. This decreases the trust of the feedback for teachers as a whole (and reliability of the system).

Anonymity takes away the opportunity to ask the student what they meant when they gave the feedback. At the moment the teacher does not have the opportunity to ask for further explanations/.../It is possible right now to appeal on the teachers anonymously and the teacher is in a complicated situation because all sorts of things could be written in there. The teachers are unprotected, it is a foolish situation (SS3).

A part of the participants suggested that the feedback should not be anonymous. It was explained, that a feedback with a name next to it would give an opportunity to a teacher ask for explanations when it is needed and even give their own statements. Another part of the participants found, that even though anonymous feedback has its weaknesses, it still should not be changed (attaching the student's name to their feedback) because it could possibly cause conflicts and/or affect the students will give negative feedback.

I think, that if the name of the student was public, then negative feedback would not be given at all. If I knew, who gave the negative feedback I would find it difficult to communicate with them in the future (M7).

Participants who recommended the feedback system to be made not anonymous pointed out, that in this way the teachers would have the opportunity to analyze the results of the feedback. They gave examples where feedback was given by students whose participation rate was low so they could not have gotten the full experience of the course because of themselves, not the teacher.

The whole system should be thought through reasonably. Sort out students, who have not seen the teacher and not understood the base of the subject/.../If I could see, if the student who gave the feedback has taken part of the course and what their grades are like then it would be possible to make some connections (SS3).

The previous study including teachers from the University of Tartu showed, that the student feedback anonymity is a problem for teachers [4]. Still, it is a recommended method in literature so that the students could give their adequate opinion without having to fear the reaction of the teacher [2]. The authors of this research paper think that one of the solutions would be to give the students an option to give their feedback either anonymously or not. The same system is used in the University of Kuopio in Finland [27], where feedback system is kept anonymous but the students are still encouraged to add their name to the feedback to make the feedback system more multifaced.

Next, to the previous it was brought out in the recommendations about the management of collecting the feedback that 3 ) the time when feedback is collected. The participants expressed different expectations about the time feedback is collected. There were some, who thought that feedback should be collected centrally at the end of the semester, after completing all the tasks in the subject (when the student has passed the course). This way the student has an overview of the subject as a whole. Others suggested a system, that would give students the opportunity to give feedback whenever they want and the teacher to follow the feedback as it comes.

In many universities, feedback is collected centrally rather than once per course, which offers to get consistent opinions about the course as a whole as well as current feedback which help make changes during the semester [6]. The authors of this article think, that this kind of a system could be a compromise version, that can be used in the discussions about the development of the feedback system. It would also be an option to leave the decision of when the feedback will be collected to the teacher (option to choose the time of giving the feedback in the info system when opening the course) and the second feedback to be collected at the end of the semester.

2) Content of the collected feedback recommendations included two bigger subjects: the importance of the answers in writing and the opportunity to change the feedback questions.

It was explained, that the feedback questionnaire should be focused to open questions. The teachers say, that feedback in writing is more valuable (informative) than a score in numbers.

The ones who really wish to give feedback are the ones whose answers are the most reliable. "Everything was OK" is not feedback. If someone has taken the time to write something next to the dots then it is reliable/.../The thing is reliable when someone has taken the time to write it (M7). 
A study conducted by Karm and colleagues showed that similar to this study the teachers believe the answers in writing to be more valuable and informative than the ones in numbers [4]. Also, in this study some of the participants that the feedback given by students would get feedback from the teachers - so that the system would include both sides. The authors see making giving students feedback one of the tasks of the teacher as another opportunity. That way the students would feel that their feedback is valued and would direct teachers to reflect on the given feedback.

The second subject, that came to the surface when discussing the content of the feedback was the teacher's suggestion to make it possible to edit the feedback questions - teachers should be able to add questions and make choices. As a reason, it was brought out that teachers are different, therefore, they need different questions.

As the third subject recommendations about including both teachers and students to the process stood out in the interviews with the teachers. The participants said, that the feedback system as a whole needs to be talked through with 1) teachers as well as 2) students. Trough this, teachers knowledge of the ways feedback results are used would increase and what is expected from them about their skills and qualities.

Teachers should be included in the process. Talk it through, what is the main goal of the feedback. Discuss, to make the questions reasonable. Then the teachers would see, that they benefit from it (SS3).

Teachers who took part in this study found, that the goals of collecting feedback should also be discussed with the students. They say, that through this the number and quality of answers would increase. It was found, that when students would understand why they need to give feedback and how it affects their study process then they would put more into their feedback.

Previous studies [2] have also found, that involving the students in the improvement of the feedback system could be an opportunity to raise their motivation about giving the feedback. It is especially important, that the students know what goals their feedback would be used towards. At the moment, it is not known exactly what are the student's opinions and attitude about giving feedback. Finding out the students position on this subject could be the next research object. For example, a quantitative survey could be conducted among all students and according to the results put together a questionnaire for teachers or conduct individual or focus group interviews.

\section{CONCLUSIONS}

This study points to the shortages in the current feedback system from the university teachers perspective and describes the expectations and recommendations for the improvement of the system. Results show that feedback is necessary for various reasons for the participants. On the one hand, its role is understood as a chance for professional development. On the other hand, feedback is considered to be a means of external control, which leads to decisions in human resources with reelecting professors within the department. Collecting feedback is beneficial for the students, teachers, the university and society as a whole.

The participants of this study have different attitudes towards collecting student feedback, explaining it with trustworthiness. The participants evaluated open-ended comments (instead of numbered ratings) as more professional development support. The expectation that collecting feedback should use more open-ended questions was implied, although it would make data analysis more demanding for the teachers.

Regardless, the participants made the point of the importance of collecting student feedback. They stated that is should be collected methodically correctly and trustworthy. The participants expressed that feedback would be seen as more reliable if it was given by all or most of the students. Since the current system in the sample of a higher education establishment it does not demand every student to evaluate all courses, the numbers of evaluations are often low and can not be generalized. Therefore, the teachers suggested increasing the percentage of the answers. One of the ways to improve was said to be making giving feedback mandatory, but students motivations were also said to be important. If students motivation were higher, their answers would be more adequate and they would explain their feedback more thoroughly. Some teachers wished, that the feedback system would be more flexible to fit different courses individualities. The teachers also suggested collecting the feedback in the middle of the semester which would give teachers the chance to make changes during the course accordingly. 
In conclusion, it can be said that giving feedback is a subject which can be used to guide students teaching and learning. Even though this study was a small-scale study, it still gave some points of discussion on the ways the feedback system could be improved. As a bonus of this study, the teachers who took part in the interviews had the chance to reflect on the feedback system and the way it has affected their way of teaching and what are their expectations towards the system.

\section{REFERENCES}

[1] H.W. Marsh, "Students' evaluations of university teaching: Dimensionality, reliability, validity, potential biases and usefulness," in The scholarship of teaching and learning in higher education: An evidence-based perspective (R.P. Perry and C. Smart, eds.), pp. 319-383, Dordrecht: Springer Netherlands, 2007.

[2] S.L. Benton and W.E. Cashin, Student Ratings of Teaching: A Summary of Research and Literature. Ithaca: Cornell University, 2012.

[3] P. Spooren, B. Brockx, and D. Mortelmans,. "On the validity of student evaluation of teaching the state of the art," Review of Educational Research, vol. 83, no.4, pp. 598-642, 2013.

[4] M. Karm, A. Sarv, and P. Pruulmann-Vengerfeldt, “Üliõpilaste tagasiside õppejõu pilgu läbi uskuda või mitte?" KVÜÕA Toimetised, no. 20, pp. 28-47, 2015.

[5] K. Edström, "Doing course evaluations if learning matters most," Higher education research \& development, vol.27, no. 2, pp. 95-106, 2008.

[6] M. Huxham, P. Laybourn, S. Cairncross, M. Gray, N. Brown, J. Goldfinch, and S. Earl, "Collecting student feedback: a comparison of questionnaire and other methods," Assessment \& Evaluation in Higher Education, vol. 33, no.6, pp. 675-686, 2008.

[7] H. Alves and M. Raposo, "The measurement of the construct satisfaction in higher education," The Service Industries Journal, vol. 29, no. 2, pp. 203-218, 2009.

[8] J. Douglas, A. Douglas, and B. Barnes, "Measuring student satisfaction at a UK university," Quality assurance in education, vol. 14, no. 3, pp. 251-267, 2006.

[9] J. Rowley, "Designing student feedback questionnaires," Quality assurance in education, vol. 11, no. 3, pp. 142-149, 2003.

[10] J.T. Richardson, "Instruments for obtaining student feedback: A review of the literature," Assessment \& Evaluation in Higher Education, vol. 30, no. 4, pp. 387-415, 2005.

[11] S. Bolhuis, "Towards process-oriented teaching for self-directed lifelong learning: a multidimensional perspective," Learning and Instruction, vol. 13, pp. 327-347, 2003.

[12] D. Kember, D. Leung, and K. Kwan, "Does the use of student feedback questionnaires improve the overall quality of teaching?". Assessment \& Evaluation in Higher Education, vol. 27, no. 5, pp. 411-425, 2002.

[13] H.-S. Haaristo, Üliõpilaste tagasiside Eesti kõrgkoolides. Tallinn: Poliitikauuringute Keskus Praxis, 2014.

[14] L. Arthur, "From performativity to professionalism: lecturers' responses to student feedback," Teaching in Higher Education, vol. 14, no. 4, pp. 441-454, 2009.

[15] F. Nasser and B. Fresko, "Faculty views of student evaluation of college teaching," Assessment \& Evaluation in Higher Education, vol. 27, no. 2, pp. 187-198, 2002.

[16] T.N. Beran and J.L. Rokosh, "Instructors' perspectives on the utility of student ratings of instruction," Instructional Science, vol. 37, no.2, pp. 171-184, 2009.

[17] D. Crumbley and E. Fliedner, "Accounting administrators' perceptions of student evaluation of teaching (SET) information, "Quality Assurance in Education, vol. 10, no. 4, pp. 213-222, 2002.

[18] J. Douglas and A. Douglas, "Evaluating teaching quality," Quality in Higher education, vol. 12, no. 1, pp. 3-13, 2006.

[19] S. Moore and N. Kuol, "Students evaluating teachers: Exploring the importance of faculty reaction to feedback on teaching," Teaching in Higher Education, vol. 10, no. 1, pp. 57-73, 2005. 
[20] M.M. Barth, "Deciphering student evaluations of teaching: A factor analysis approach," Journal of Education for Business, vol. 84, no. 1, pp. 40-46, 2008.

[21] Haridussilm, Accessed 18 November, 2017. Retrieved from http://www.haridussilm.ee/

[22] Tartu Ülikool. Ülikoolist, Accessed 13 December, 2017. Retrieved from https://www.ut.ee/et/ulikoolist/

[23] Õpetamise ja õppeainete tagasiside, Accessed 9 December 2017. Retrieved from https://www.ut.ee/et/oppimine/uliopilasele/lisaoigused/oppeainete_hindamine/

[24] K. Roosimäe, Graphs of feedback results, 2012. Retrieved from https://wiki.ut.ee/display/oppijale/Graphs+of+feedback+results/

[25] V. Braun and V. Clarke, "Using thematic analysis in psychology," Qualitative Research in Psychology, vol. 3, no. 2, pp. 77-101, 2006.

[26] T.D. Johnson, "Online student ratings: Will students respond?" In Online student ratings of instruction: New Directions for Teaching and Learning (T.D. Johnson and D. L. Sorenson Eds.), pp. 49-59, San Francisco: Jossey-Bass, 2003.

[27] The student feedback system in the University of Kuopio, Accessed 12 December 2017. Retrieved from

https://www2.uef.fi/documents/13384/1401124/feedbacksystem_english.pdf/f5a6fadc-6e4743e4-b40d-0c1ab71ed494/ 